\title{
FAILING WITH SUCCESS
}

\author{
A study of e-commerce adoption and knowledge transfer to small \\ and medium-sized enterprises in Sweden
}

\author{
FRANK ULBRICH \\ Stockholm School of Economics, Department of Information Management, Sweden
}

\begin{abstract}
An e-commerce dissemination project for small and medium-sized enterprises is analyzed to determinate its successfulness. After a theoretical discussion of different success measurements, different phases of the dissemination project are examined from different perspectives by representing the three different groups of participants - project management, consultancies, and small and medium-sized enterprises (SMEs). Understanding the process of carrying out a dissemination project will help to identify determining factors for the successfulness of such projects which in fact depends on the different perspectives presented in this paper.
\end{abstract}

\section{INTRODUCTION}

The European Union (EU) supports many information and communication technology (ICT) dissemination projects, even if the rate of success is questionable.

Over the past years, European politicians expressed their wish to strengthen Europe's economic wealth, resulting among others things in the EU's e-Europe initiative. Turner (2001) describes how Europe might achieve a leading position in the global market. He emphasizes that companies of all sizes need to improve their competitive advantages. Callon (1996) believes that this can be achieved by widely using modern and innovative ICT. One example for innovative ICT is e-commerce. The EU expects e-commerce to become a technology that will give European companies competitive advantages in the global market. This assumption is confirmed by the fact that many e-commerce projects were initiated and/or funded by the EU or its

The original version of this chapter was revised: The copyright line was incorrect. This has been corrected. The Erratum to this chapter is available at DOI: 10.1007/978-0-387-35692-1_36 
memberstates in recent years.

But are the high expectations really justified? And what price do companies have to pay to obtain a competitive advantage through e-commerce?

Shapiro and Varian (1998) point out the risk of becoming dependent of technology even if it probably will help to achieve competitive advantages. Porter (2001) states that the majority of basic economic principles will most likely not change when adopting e-commerce and that technology per se will not generate any benefits or competitive advantages. McKenna (1997) shows that modern technology will significantly influence the way of doing business by helping companies to meet their customers' demands. Following the customers' requests to provide more individual services, Davis and Davidson (1991) state that companies need to capture and utilize information about their customers at each stage of contact, and not only a few. This will, according to Hagel and Armstrong (1997), revamp competitive and managerial situations. Consequently, ICT becomes more and more a significant part of doing business.

However, it has to be asked whether companies are prepared to handle the new situation. Especially small and medium-sized enterprises (SMEs) do not often have enough knowledge about how to use a new technology efficiently. Here, ICT dissemination projects come into the picture. Different projects are run to accelerate the implementation of e-commerce among European SMEs, aimed to help European companies to quickly become more competitive.

Considering the great amount of ICT projects carried out, it is of particular interest to investigate whether such projects actually succeed.

\subsection{Objective of the paper}

The objective of this paper is to deal with a particular ICT dissemination project, which was conducted in Sweden, to determine its rate of success. After discussing success criteria, different perspectives from the project management, consultancies, and SMEs will be used to find factors and interrelations between them to determine the successfulness of the dissemination project.

The findings are considered to be of primary interest for those dealing with project management in similar projects and/or those deciding to fund such projects. 


\section{A SHORT PROJECT DESCRIPTION}

An e-commerce dissemination project run by the Blekinge Institute of Technology during the year 2000 was the starting point for this study. The project was called "Companies in cooperation meeting tomorrow's challenges" (in Swedish: "Företag i samverkan möter framtidens utmaningar"). Its objective was to raise the participating SMEs' ability of being competitive by supporting them in the process of implementing electronic commerce (cf. Länsstyrelse Blekinge 1999).

At the point the project was granted it could be observed that smaller companies would be forced more and more by larger companies to implement some form of e-commerce. Therefore, the participating companies should be helped to survive in an increasingly competitive market. The project focused on subcontractors to larger Swedish companies, and the basic idea to start with the larger companies' demands.

Initially, the dissemination project was designed to consist of three different phases:

1. The first phase included competence improvement, where companies should have been made more aware of benefits with e-commerce. As a measurable result, 150 companies should participate in such activities and even more should be reached by mailing information about such activities.

2. The second phase was planned to consist of cooperation and collaboration between the participating SMEs. During this phase, at least 25 companies should have created local networks, partly in order to discuss problems and ideas with each other, partly to see whether there could be some cooperation between them.

3. Finally the third phase should include analysis of the 25 project participants' businesses in order to present individual action plans on how to implement e-commerce. The third phase was meant to be accomplished by external consultancies.

\section{METHODOLOGICAL APPROACH}

Some researchers believe that there is no such thing as a best research method. Often, a combination or modification of research methods is used for certain purposes. Schein for example argues, "there is no one best way, and that what we must strive for is a deeper understanding of each of the many ways to further our knowledge of human systems" (Schein 1986, p. 9).

Therefore, it is actually irrelevant to question whether to use quantitative or qualitative research methods or techniques in isolation. "Important is, 
instead, the congruence between the scope of the research and the method we have chosen in order to realize this scope." (Berg 2000, p. 9). In order to gain a better understanding in the research object it is therefore important to perceive reality as it is. Lundeberg (1993) believes that shifting between different perspectives will help the researcher to better perceive reality as it really is. Therefore, three different perspectives are used when describing and analyzing the empirical data: a) a project management perspective, b) a consultancy perspective, and c) a SME perspective. Data collection was conducted by participating observation and interviews with participants.

\section{BACKGROUND}

\subsection{Small Enterprises}

The average company that participated in the analyzing phase of the dissemination project had between 25-50 employees and was family-owned. Three areas were focused on in the literature review. These areas were connected to: 1) SMEs economic growth; 2) expectations for the future; and 3 ) enhancement of working conditions in SMEs. These areas were chosen partly because of their connection to the objective to achieve better positions in competing markets, partly because of the SMEs motivation to participate in the project.

Emling (2000) shows that family-owned companies in Sweden are usually not especially interested in economic growth, but rather like to know how costs would develop in the future. Many of the companies seemed to be pleased with their current situation and did not strive to become a larger company. Schumacher (1975) already described this behavior when arguing for keeping a business small instead of focusing on expansion.

Concerns about the future were also expressed, primarily on how technology could be used to improve a company's competitiveness. Many previous studies showed that companies could achieve competitive advantages through the use of modern innovative ICT (cf. e.g. Hardes et al 1993; Callon 1996).

Finally, improving working conditions and life-style of the owners was an addressed field. Enhancing the owner's quality of life was found to be important in SMEs (cf. Westhead et al 1996; Ulbrich 2000). Here the main concerns of owners were about getting more spare-time and /or higher revenues, which they could benefit from. 


\subsection{Success and failure criteria}

Success and failure are concepts that are used in different ways by different authors. Mirvis and Berg (1977) e.g. describe success and failure from an organization development context and state that, besides demands from organizations, our understanding of success and failure even is characterized by cultural influences. They mean that parents e.g. hope for a better life for their children. Mirvis and Berg (1977, p. 8) state that, "to foster and sustain these values our culture associates success with hard work and competence. At the same time it equals failure with indolence and inability."

Our perception of success and failure is influenced by what we learn from parents, teachers, institutions and so on. Therefore, success and failure are often measured in terms that people consider being good or bad at a certain time in a certain cultural environment. Trying to measure if something has been successful or not, has kept researchers busy for decades. They are often looking for objective measurements such as productivity. Marrow (1972) did so when e.g. describing whether changes in the automotive industry had been successful or not. He could find that productivity, and by those means, success, was influenced by technology. If new technology had been applied in a way that increased productivity, a successful implementation had taken place.

Other explanations for success can be found in an encyclopedia. In Brockhaus (1979) e.g. one explanation is connected to economics and measured as profit and loss within an organization, meanwhile another one is based on psychology. The second states that success is the experience of confirmation when successfully realizing a self-set target, which is specified by one's own level of claim and performance motivation. This explanation is totally subjective and can therefore only be measured by the person who set his/her own goals.

Consequently, success and failure can be measured in different ways. Therefore, one has to decide how and what to measure. Kahn $(1975 ; 1988)$ e.g. measures success and failure in export industries. He initially decided to use an objective and a subjective criterion when measuring failure and success. Kahn (1975) decided to use pre-tax profit and sales as a criterion for objective measurement. This is in accordance with others, such as Marrow (1972), where success or failure can be expressed in numbers and economic terms. As a subjective measurement Kahn (1975) uses an internal assessment to measure the degree of success and failure of a given venture. $\mathrm{He}$ investigates the degree to which expectations are met by comparing actual outcomes with expected outcomes regarding a number of criteria such as costs, export volume, profitability etc. This way of measuring success and 
failure is in line with the psychological explanation of the encyclopedia (Brockhaus 1979) and puts individuals and their perceptions to the forefront. Several years later, Kahn (1988) decides to change some of the subjective measurements to what he calls semi-objective. The degree to which expectations are met compared to the actual outcome, is moved from subjective to semi-objective and only individual statements are left as subjective. Furthermore, Kahn (1988) could observe that success and failure were not measured in equal terms in Sweden and Japan and confirmed Mirvis and Berg's (1977) statement on cultural differences in our understanding of what success and failure is.

When discussing and measuring success and failure in this paper, a trisection, as suggested by Kahn (1988) with minor modifications for the purpose of investigating ICT dissemination projects, is used: 1) objective, pre-tax profit and sales; 2) semi-objective, as a degree to which outcomes fulfilled project requirements; and 3) subjective, as an internal assessment to which individuals' expectations were met compared to the actual outcome.

\section{PROJECT ACCOMPLISHMENT}

The dissemination project was performed in three successive phases. But in contrast to the three phases the project was initially divided into (cf. A Short Project Description), project management decided to change the order of these sequences. Phase two (cooperation and collaboration between the participating SMEs) and three (analyzing businesses of 25 project participants) were performed in parallel and before the first phase (competence improvement). Project management decided to do it in this way, as it felt the need to inform the local SMEs about definite findings from the region, rather than theories on electronic commerce or best practice from companies the local SMEs could not identify themselves with.

\subsection{Phase I: Initializing}

The dissemination project started with an initializing phase where project management's tasks were to rewrite the original project plan and to receive approval. Activities and states of Phase I are pictured in Figure 1.

After creating the new version of the project plan, the next activity was to inform SMEs and external consultancies about the project. It was necessary to find at least 25 SMEs that wanted to participate in the project. One of the project managers had been working at the Chamber of Commerce and Industry of Southern Sweden previously and had been in contact with several local SMEs, which would give him access to more than 200 SMEs. 
Project management decided to contact those companies where they assumed or knew that the SMEs could be interested in participating in an electronic commerce project. In this way participating SMEs were handselected without spreading information about the project's existence to a broader audience.

In parallel, project management decided to contact a number of consultancies that could fit the project's requirements. The project budget included financial means for only some external consultancy hours. Therefore, consultancies that were willing to donate some of their services, seeing the participation in the dissemination project as a strategic investment into their future electronic commerce ventures, were attracted to the dissemination project. In return a so-called Round Table was set up for consultancies to share ideas and discuss all kind of issues encountered during the project. Furthermore, the consultancies were promised early access to the results from the other consultancies before the participating university would publish any findings about the project.

Three consulting firms were contracted and meetings between one consultancy and 8-12 SMEs were conducted. During the meetings the invited SMEs were informed about the purpose of the project as well as the consultancy's way of carrying out individual analyses of the SMEs.

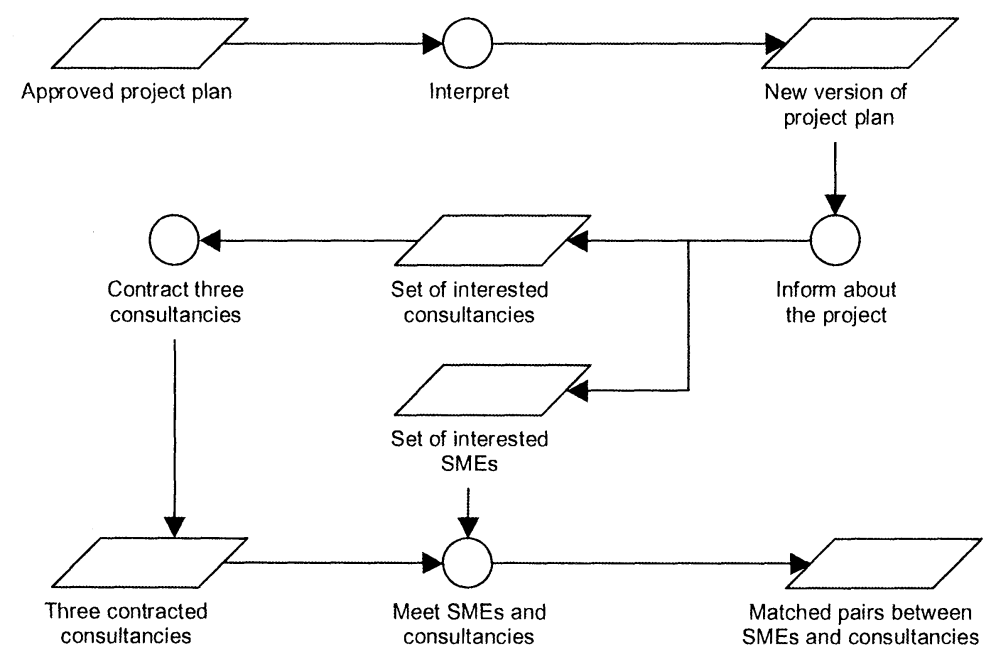

Figure 1. Initializing phase

After the initial meetings some of the SMEs dropped out and others were considered inappropriate for the project due to lack of interest or preconditions such as the size of the business. Project management and the 
consultancies decided together which SMEs would participate in the second phase.

\subsection{Phase II: Accomplishment}

In the second phase (cf. Figure 2) the "real work" was carried out. The participating SMEs had a number of individual meetings with their assigned consultancy. Project management's role in this phase was to help the consultancies to establish contact with the SMEs and to keep alive a discussion between the consultancies, which was done by organizing three Round Tables where results and problems with the project were discussed.

In parallel with activities in Phase II, project management prepared the third phase.

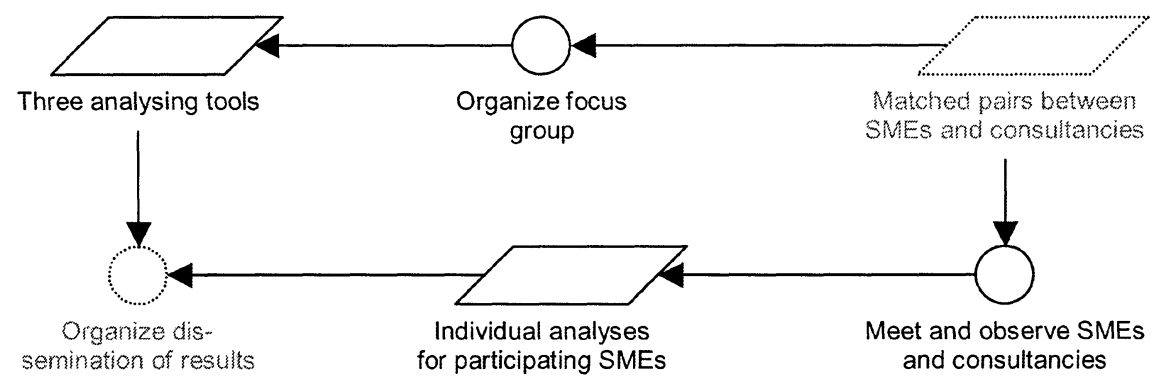

Figure 2. Accomplishment phase

\subsection{Phase III: Dissemination}

The last phase concentrated on dissemination and evaluation of the project (cf. Figure 3). According to the approved project plan, information about electronic commerce needed to be spread to at least 150 SMEs in the region. Project management invited local SMEs to an e-commerce conference where the purpose was to inform about e-commerce in general and possible solutions for SMEs in particular. The consultancies were also invited to talk about their experiences of the project using one or two companies as case studies.

After the conference, findings from the projects and some further project documentation were collated in a final project report. This report was circulated to all participants and invited companies at the conference. 
In addition to the synthesis, two researchers from the Blekinge Institute of Technology evaluated the project. Their evaluation showed that the project was performed according to the requirements stated in the revised project plan.

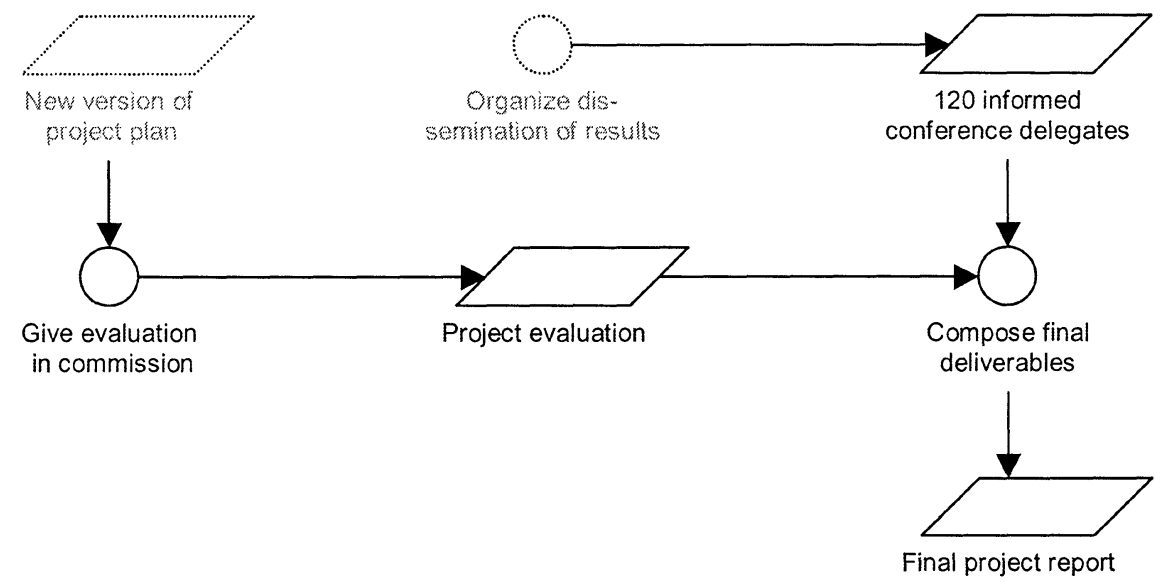

Figure 3. Dissemination phase

\section{$5.4 \quad$ Was it a success?}

The final project evaluation concluded that the project had been performed according to the requirements. The external evaluators could only evaluate the visible surface of the project using a semi-objective perspective. An insider might have had more insight as to the project's progression and all the problems that had been handled at certain times. Therefore, an observer who had the possibility to monitor all different stages in the process would have had more opportunity to look beyond the black box and beyond the surface, to question whether the project was a success.

\section{UNDER THE SURFACE}

In the first phase it seemed that project management put a lot of effort into selecting the $25 \mathrm{SMEs}$ that would be asked to participate in the project. The project manager, coming from the Chamber of Commerce and Industry of Southern Sweden, performed this task, as he already knew many of the regional SMEs. He contacted 32 SMEs in the selection process that he thought might be interested in participating. 
One reason behind the fast selection process was because the time frame for the project was quite limited. It was already spring when the first companies were contacted and individual analyses should be finished by the end of autumn. It is very difficult to set up meetings during the long Swedish vacation period (mid-June to mid-August). Therefore, the project manager wanted to finish the selection process as quickly as possible.

At the first general meeting between 11 SMEs and one of the consultancies it come to light that the selection process had not been very effective. After a presentation about how the consultancy wanted to carry out the project, the SMEs were asked how they thought electronic commerce could make a contribution to improve their businesses. From the answers some of the participants' expectations about the project and their knowledge about e-commerce could be derived. While one person e.g. could state exactly what his company needed-which was an implementation of an EDI solution in order to be able to stay in business as subcontractor in the Swedish car industry-another did not even know why he was joining the meeting-which he expressed by the statement that his boss had sent him to the meeting just to hear what it was about. These statements also show the wide array of understanding about e-commerce. Companies which already knew about e-commerce and how it might be adopted in their businesses, were much more engaged in the initial meetings and appeared more motivated to participate in the project than those without pre-knowledge. Pre-knowledge on electronic commerce would be one factor that would probably influence the outcome of such a project.

Even the relation between project management and the SMEs influenced the motivation factor. Earlier contacts and probably also personal relations between persons in the SMEs and the project manager, who earlier worked at the Chamber of Commerce and Industry for Southern Sweden, may have influenced the relationship between the project manager and the SMEs. This could be observed, since it appeared that some SMEs did not join the project because of its content. In many cases companies accepted the invitation to participate in the project because the CEO and project manager knew each other and sometimes it may have been commanded by feelings such as guilt ("I have to help them with this unpromising situation."), rendering a service ("Well, in return for my service they will have to help me next time.") or avarice ("If we participate now, it will look good to get something for free in the future."). Thus, Motivation to be part of the project was influenced both by feelings and personal contacts that were based more on content.

The relationship between the abovementioned factors could be summarized as a group of driving forces for the SMEs (cf. Figure 4). 


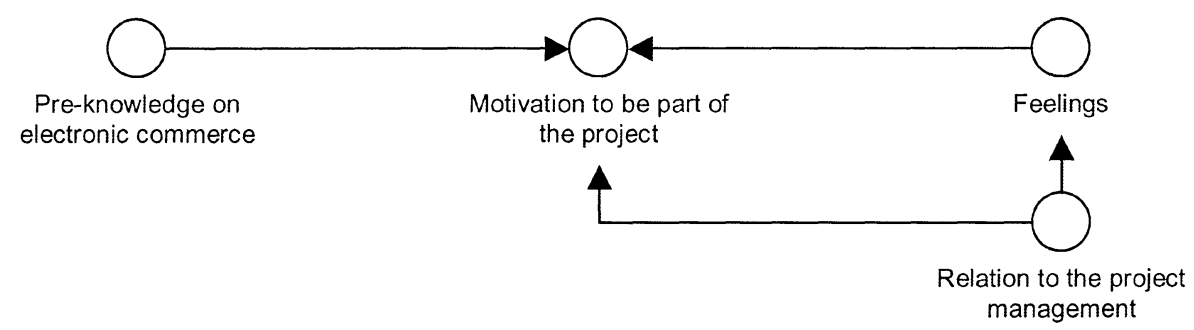

Figure 4. Driving forces for SMEs

Motivation and pre-knowledge are factors that affected the project's progress. Overall it could be stated that those companies who had preknowledge and were more motivated also played a more active role in the second phase of the project. In these companies, meetings with the consultancies went without mentionable incident, whereas the other companies sometimes felt compelled to cancel an appointment or did not show up with the personnel that were required. For instance, one of the SMEs called a project manager and asked him to move a meeting with the consultancy to the day after because they wanted rather to meet with a client. It was obvious for the project manager that the new meeting with the client would not be critical for the company's survival in the future, but they preferred it anyway. In another example an SME did not call all responsible managers to a meeting with the consultancy even if they earlier agreed to do so. The CEO simply did not see the need of having all managers gathered at the same time and he considered himself as the one who knew the company best of all.

This shows that tactical issues came before strategic. As the project was more of strategic nature, the degree of active participation in the SMEs was directly influenced by motivation and pre-knowledge.

Active participation also influenced two goals of the projects. One was directly influenced, the degree to which extent suggestions would be usable for SMEs, i.e. the degree of how likely SMEs will adopt the suggestions of the consultancies after the project was completed. An unexpressed goal for project management was that $80 \%$ of the participating SMEs should declare that the project was useful for them in the future. But the consultancies doubted from an early stage whether this could have been achieved. The inability to adopt new ways of thinking how to conduct business by using electronic commerce seemed to affect this goal. The other goal was to establish at least three new networks among the participating SMEs, as stated in the project plan. To establish new networks, of course, depended on the SMEs' wish to be included. If SMEs could see good reason to join the network they probably would have done so, but to create an Interest to join a 
network was influenced by the SMEs motivation as well as active participation.

During the second phase the interrelation between different factors affecting the outcomes of the project from the SME perspective increased the driving forces and active participation as shown in Figure 5.

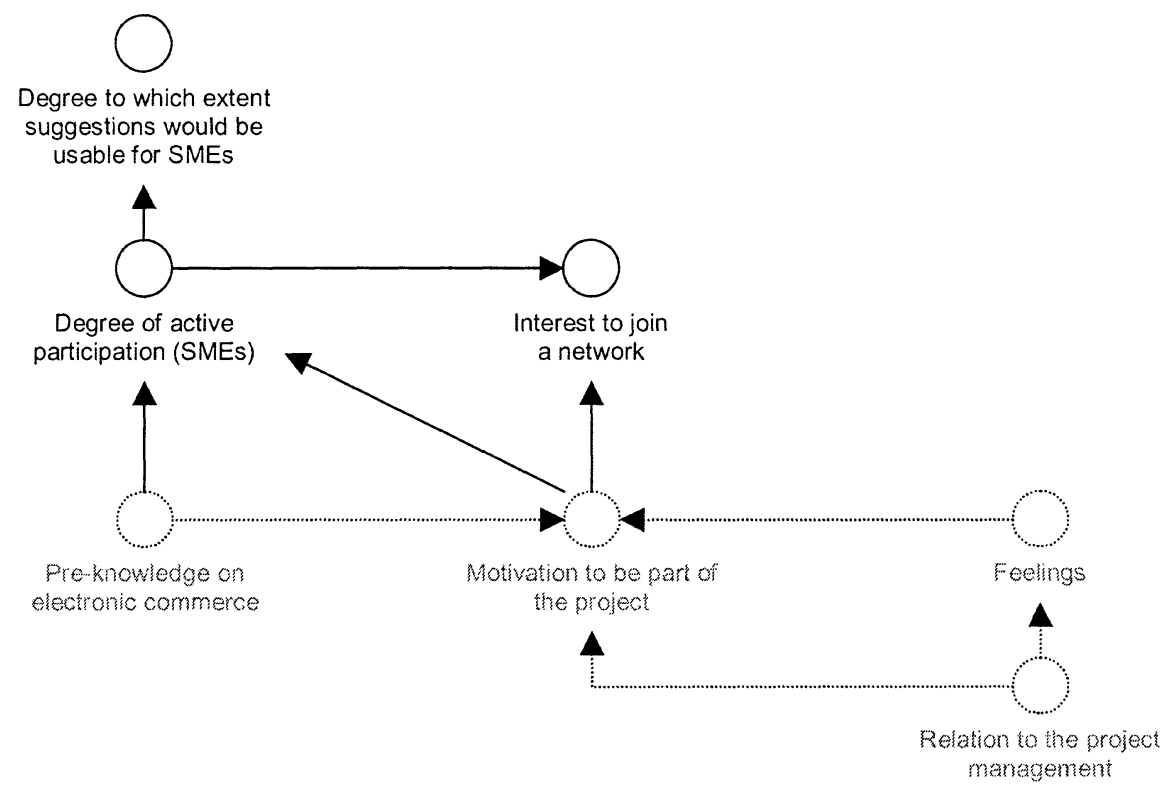

Figure 5. Driving forces and active participation in SMEs

\subsection{Shifting perspective}

To achieve a high degree of usability is not only dependent on the SMEs. So far we have only discussed factors that described levels and states to the SMEs and how these will affect the outcomes of the project. We already started to see connections to the project management as well, but for now let us leave the SME perspective and look closer at what happened within the three consultancies.

The degree of usability is e.g. to a high degree dependant on the efforts of the consultancies. It was shown to be a problem that the three consultancies were all large well-established consultancies. One of them operated on a global level, one of them on the European market and one of them on the Swedish market only. 
The average customer for these consultancies usually were large, often multi-national, companies with long-term commitments in fields such as outsourcing, system development and user training. Assignments like the one in this project, to analyze an SME within a fraction of hours they usually could use for similar task within larger companies, demanded a new way of thinking. So it seemed crucial that the consultancies would succeed in developing new ways to produce usable consultancy reports. New methods and tools for analysis were needed in order to carry out analysis under the circumstances the project demanded.

As already stated in the short project description, getting access to each other's analysis tools should partly compensate the consultancies. So it was not only the development of analyzing tools but also the consultancies' willingness to cooperate, those were factors behind the desired degree of usability (cf. Figure 6).

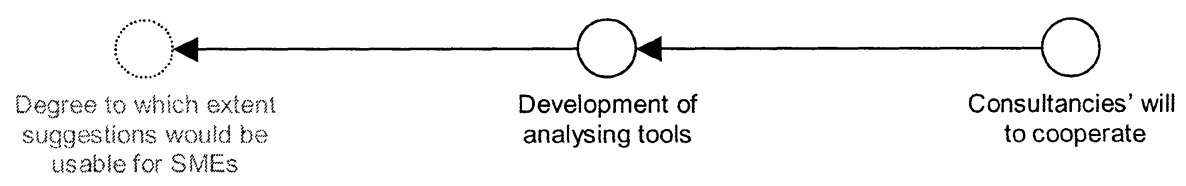

Figure 6. Creating preconditions for analysis

The development of the analysis tools was incumbent on the consultancies, but in order to share experiences from an early stage and to learn from each other, the consultancies agreed to participate in Round Table meetings.

The Round Table meetings turned out to be the place where the consultancies were more willing to listen than to share their new ideas. Information that was shared with the other consultancies was mostly information that was later documented in the consultancies' reports, but did not offer much to the development of new analysis tools. One of the consultants summarized the Round Table meeting by stating after the last one, that nothing was actually achieved that was not already known. His observation turned out to be correct. The desire to cooperate in order to achieve competitive advantage against other consultancies, who had not participated in the project, was overshadowed by the fact that the companies still saw themselves as competitors. Some ideas about how to do such an analysis might have come up at the consultancies, but they were neither discussed at the Round Table, nor reflected in the analysis tool description that each consultancy provided in the end of the project. One consultant reported afterwards that there was no profit in SME e-commerce, and this 
might explain why one of the three consultancies did not show much interest at the Round Table meetings and did not apply much effort on developing new analysis tools.

\subsection{Shifting perspective}

For the project management it was a preferred goal to achieve some common analysis tools. The project management expected that such a tool should even be valid for SMEs without the help of a consultancy in order to increase SMEs pre-knowledge before taking further steps to implement electronic commerce and before even talking to a consultant. Therefore, increased pre-knowledge could result in a positive circle with higher degrees of motivation and active participation. But the consultancies did not wish to develop such tools that should be given away for free. Thus, the Development of free tools for SMEs was strong depending on the Consultancies' will to provide free tools (cf. Figure 7).

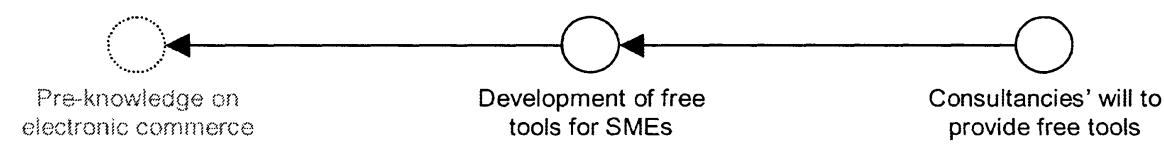

Figure 7. Supporting SMEs in knowledge build-up

Unfortunately, this never happened during the project. The consultancies either did not develop such tools, or did not inform the others that they did so. The only tools they used were different kind of questionnaires where SMEs were asked to prepare themselves before a meeting but these questionnaires were not transparent for the SMEs and therefore did not serve the knowledge build-up in SMEs.

\section{CONCLUSIONS}

Regardless of how the project ended, the participating organizations learnt about themselves and how they could apply e-commerce in the future. Whether it is really concrete, such as a forthcoming implementation project or just the insight that the organization is not ready to use e-commerce at the moment, organizations might benefit from participating in the project from an organizational development standpoint. Even if one might call the project 
a failure the insights can be useful for the single participating organization. Therefore, the project can be seen as a success.

Others might say that the project where only the formal goals were achieved, but the participants decided not to pursue their own implementation, was a complete disaster. In this case, projects that are indicated not to be followed up or carried on by the participants should neither be supported nor started at all.

From a third point of view, it could be argued that the project was a success despite some failures. This means that the project management could not be hold responsible for what the participants would do after the project and that it is only of interest that the formal project requirements were fulfilled.

Concluding it can be stated that the particular project described in this paper could be classified as a success, a complete disaster or a success despite failure, depending on how one would like to look at the results. A combination of the three different views could be called as "Failing with Success".

\section{REFERENCES}

Berg, P. O. (2000), Is There a Clinical Research Method? Stockholm School of Entrepreneurship, draft.

Brockhaus (1979), Der grosse Brockhaus, Bielefeld: Bertelsmann Verlag.

Callon, J. D. (1996). Competitive advantage through information technology, New York, McGraw-Hill.

Davis, S. and Davidson, B. (1991), 2020 vision. New York, Simon \& Schuster.

Emling, E. (2000), Svenskt familjeföretagande, Stockholm: The Economic Research Institute.

Hagel, J. and Armstrong, A. G. (1997), Net gain: expanding markets through virtual communities, Boston, Mass.: Harvard Business School Press.

Hardes, H. D., Krol, G. J., Rahmeyer, F. and Schmid, A. (1993), Volkswirtschaftslehre, Tübingen: UTB für Wissenschaft.

Kahn, M. S. (1975), A study of success and failure in the Swedish export industry: an empirical study of fourteen firms in three manufacturing industries, Stockholm: Stockholms Universitet - Forskningsrapport.

Kahn, S. (1988), Success and failure of Japanese companies' export ventures in high-tech industries: a comparative study of Japanese and European manufacturing companies' export marketing and investment strategies in ASEAN, the NIEs and the People's Republic of China, Stockholm: Almqvist \& Wiksell International.

Länsstyrelse Blekinge (1999), 'EG:s strukturfonder beslut 1999-10-25', Dnr. BL 2.41-41-99, Karlskrona.

Lundeberg, M. (1993), Handling change processes: a systems approach, Lund, Bromley: Studentlitteratur, Chartwell-Bratt.

Marrow, A. J. (1972), The failure of success, New York.

McKenna, R. (1997), Real time: prepearing for the age of the never satisfied customer, Boston, Mass.: Harvard Business School Press. 
Mirvis, P. H. and Berg, D. N. (1977), Failures in organization development and change: cases and essays for learning, New York.

Porter, M. E. (2001), 'Strategy and the Internet', Harvard Business Review, March 2001, pp. 63-78.

Schein, E. H. (1986), The Clinical Perspective in Fieldwork, Qualitative Research Methods Series 5, Beverly Hills: Sage Publications.

Schumacher, E.F. (1975), Small Is Beautiful, New York: Harper \& Row, Publishers, Inc.

Shaprio, C. and Varian, R. (1998), Information Rules, Boston, Massachusetts: Harvard Business School Press.

Turner, C. (2001), 'Accelerating the development of the European information economy: the European Commisson's eEurope initiative.' European Business Review 13(1), 60-66.

Ulbrich, F. (2000), A Decision-Support Framework for Electronic Commerce in Small and Medium-sized Enterprises, in 'Conference Proceedings: Innovation Through Electronic Commerce IeC 2000', Manchester, UK, Nov 14-16, pp. 211-221.

Westhead, P., Cowling, M. and Storey, D. J. (1996), The Management and Performance of unquoted Family Companies in the United Kingdom, Centre for Small and Medium Sized Enterprises, Warwick Business School, The University of Warwick. 